\title{
Pusat Batik Banyumasan dengan Pendekatan Kearifan lokal di PURWOKERTO
}

\author{
Aqmarina Safitri, Rachmadi Nugroho, Hari Yuliarso \\ Program Studi Arsitektur \\ Fakultas Teknik \\ Universitas Sebelas Maret Surakarta \\ Email : rinaaqma12@gmail.com
}

\begin{abstract}
Batik became one of Indonesia's cultural heritage that should be preserved and cultivated batik is already recognized by the international community (UNESCO) designated as a Masterpieces of the Oral and Intangible Heritage of Humanity. Purwokerto is a batik producer Banyumasan which have tourism potential of batik spreads make travelers less efficient in time to reach the points the location of batik industry. The problems that arise in the design of the center of Batik Banyumasan in Purwokerto is how efforts to plan and design a Banyumasan Batik Center that hostsrelated activities efficient batik tour for tourists. The aim is to meet the container activities related to information and promotion, sales, and production of Banyumasan Batik with the approach of Local Wisdom. Architectural design that fits this batik center planning method using Local Wsdom aspect due to the approach of considering the aspects of Local Wisdom that still exists in the local environment. The concept of a Batik Centre Local Wisdom will apply to wards the building that includes the concept of a zone of space, building orientation, shape and appearance of the building as well as the structure of the building is closely related to the element of local wisdom.
\end{abstract}

Keywords:Batik, Banyumasan Batik, Batik Center, Purwokerto, Local Wisdom.

\section{PENDAHULUAN}

Batik merupakan produk budaya Indonesia yang sangat unik dan merupakan kekayaan budaya yang harus dilestarikan dan dibudidayakan. Saat ini, seni batik sangat diminati oleh berbagai kalangan. Batik sudah diakui masyarakat internasional, oleh UNESCO telah ditetapkan sebagai Warisan Kemanusiaan untuk Budaya Lisan dan Nonbendawi (Masterpieces of the Oral and Intangible Heritage of Humanity) sejak 2 Oktober 2009, sebagai warisan budaya Indonesia. Selain sebagai karya kreatif yang sudah berkembang sejak jaman dahulu serta sebagai hasil seni budaya, maka kerajinan dan industri batik merupakan sumber kehidupan perkonomian masyarakat di berbagai kota, seperti Banyumasan, Pekalongan, Solo, Yogyakarta, Cirebon dan sebagainya, dimana masing-masing daerah memiliki corak dan motif tersendiri yang berbedabeda.

Nilai produksi batik Indonesia lambat laun semakin meningkat baik di dalam negeri sendiri maupun mancanegara, seiring banyaknya jumlah unit usaha batik.
Salah satu kota penghasil batik di Indonesia adalah Kota Purwokerto. Di kota ini terdapat corak khas batik setempat yang dikenal dengan nama Batik Banyumasan. Kota Purwokerto ini memiliki beberapa lokasi penghasil batik yang berjumlah ratusan industri dan tersebar di beberapa titik di Kota Purwokerto.

Banyaknya pengrajin batik dan corak khas batik menjadikan kebutuhan wadah kegiatan berupa Pusat batik. Pusat Batik Banyumasan ini bertujuan sebagai salah satu destinasi wisata belanja yang ada di Kota Purwokerto, yang akan mewadahi segala kegiatan mengenai informasi dan promosi, penjualan, serta produksi dan penjualan Batik Banyumasan yang diambil dari produsen-produsen asli dari titik-titik penghasil batik khas Banyumasan.

Desain arsitektur perencanaan pusat batik didasarkan pada penekanan aspek Kearifan Lokal. Pusat batik ini diharapkan membawa unsur Kearifan Lokal terhadap bangunan dengan menerapkan unsur Kearifan Lokal terhadap bentuk dan tampilan bangunan. Pusat batik ini diharapkan sebagai salah satu sarana untuk melestarikan unsur Kearifan Lokal setempat. 


\section{METODE}

Pusat Batik Banyumasan ini bermula dari pemikiran tentang upaya dalam menciptakan suatu wadah untuk mewadahi kegiatan yang berhubungan dengan wisata batik yang efisien bagi wisatawan serta berhubungan dengan informasi, promosi, penjualan, produksi, dan penjualan Batik Banyumasan

Strategi desain yang digunakan yaitu pendekatan Kearifan Lokal yang akan menerapkan beberapa prinsip Kearifan Lokal sebagai berikut:

1. Bentuk Bangunan

Wujud bangunan srotong dengan bentuk atap rondo cincing, yang terdiri dari dua bentuk dasar yaitu bentuk persegi panjang dan bentuk atap kampung dengan dua kemiringan sudut.

2. Dimensi

Penerapan pola dimensi ruang yang mengikuti dimensi rumah srotong.

3. Warna

Pemilihan warna yang diterapkan memunculkan karakter warna alami dari bahan yang digunakan pada bangunan.

4. Tekstur

Tekstur selain sebagai elemen tata ruang dalam memunculkan kekhasan tekstur Kearifan Lokal.

5. Tata Elemen Arsitektural

Penerapan beberapa ornamen pada elemen arsitektural di Pusat Batik Banyumasan.

6. Orientasi Bangunan

Orientasi bangunan mengikuti arah orientasi Gunung Slamet sebagai penerapan Kearifan Lokal pada bangunan Pusat Batik Banyumasan.

\section{ANALISIS}

Pada sub bab ini akan membahas tentang analisis perencanaan dan perancangan Pusat Batik Banyumasan, berupa peruangan, lokasi tapak, pengolahan tapak, dan struktur.

\subsection{Analisis Peruangan}

1. Tujuan: kebutuhan ruang.

2. Dasar pertimbangan: pelaku kegiatan, jenis kegiatan, dan pola kegiatan.

Tabel 1. Analisis Kebutuhan Ruang

\begin{tabular}{c|c}
$\begin{array}{c}\text { KELOMPOK } \\
\text { KEGIATAN }\end{array}$ & $\begin{array}{c}\text { KEBUTUHAN } \\
\text { RUANG }\end{array}$ \\
\hline
\end{tabular}

\begin{tabular}{|l|l|}
\hline Kegiatan Informasi & $\begin{array}{l}\text { R. Informasi, R. } \\
\text { Galeri }\end{array}$ \\
\hline Kegiatan & R. Membatik, R. \\
Membatik & Pencelupan, R. \\
& Pencucian, R. \\
& Nglorod, R. \\
& Penjemuran \\
\hline Kegiatan & R. Display, R. Ganti, \\
Pemasaran & Kasir \\
\hline Kegiatan & Kantin, Dapur, \\
Penunjang & Mushola, ATM Box \\
\hline Kegiatan Pengelola & R. Kepala, R. \\
& Sekretaris, R. Tamu, \\
& R. Karyawan, R. \\
& Rapat \\
\hline Kegiatan Servis & R. Pompa, R. Genset, \\
& R. AHU, R. Panel \\
& Listrik \\
\hline
\end{tabular}

Pada Tabel 1. terlihat kebutuhan peruangan yang dibutuhkan dalam pemenuhan wadah Pusat Batik Banyumasan.

\subsection{Analisis Luasan Ruang}

1. Tujuan: luasan ruang.

2. Dasar pertimbangan: Jenis kegiatan yang diwadahi, jumlah pelaku, peralatan pendukung yang digunakan, dan kenyamanan sirkulasi.

3. Proses analisis:

Perhitungan besaran ruang dalam pusat batik yang direncanakan sebagai berikut:

a. Kelompok kegiatan umum $= \pm 1.453$ $\mathrm{m}^{2}$

b. Kelompok kegiatan informasi $= \pm$ $208 \mathrm{~m}^{2}$

c. Kelompok kegiatan membatik $= \pm$ $162 \mathrm{~m}^{2}$

d. Kelompok kegiatan pemasaran $= \pm$ $1025 \mathrm{~m}^{2}$

e. Kelompok kegiatan penunjang $= \pm$ $264 \mathrm{~m}^{2}$

f. Kelompok kegiatan pengelola $= \pm 66$ $\mathrm{m}^{2}$

g. Kelompok kegiatan servis $= \pm 60 \mathrm{~m}^{2}$

Total luas kebutuhan ruang $= \pm 3.238 \mathrm{~m}^{2}$. Jumlah lantai $=1$ lantai

$\mathrm{BC}=5.396 \mathrm{~m}^{2}$.

Luas kebutuhan ruang $=5.400 \mathrm{~m}^{2}$.

\subsection{Analisis Lokasi}

1. Tujuan: lokasi tapak.

2. Dasar pertimbangan: tapak berpotensi bagi terciptanya nuansa Kearifan Lokal pada banguna dan luasan tapak dapat 
menampung seluruh kebutuhan ruang yang direncanakan.

3. Proses analisis:

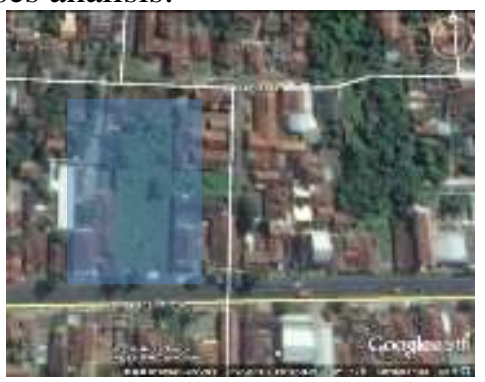

Gambar 1. Lokasi Tapak

Lokasi tapak Pusat Batik Banyumasan berada di Kecamatan Sokaraja, Kabupaten Banyumas (lihat Gambar 1).

\subsection{Analisis Pencapaian}

1. Tujuan: main entrance dan side entrance.

2. Dasar pertimbangan: kemudahan akses, sirkulasi tapak yang aksesibel, arus kendaraan dan potensi jalan, tingkat keamanan.

3. Proses analisis:

Letak main entrance berada di sisi Jalan Supardjo Rustam karena lebih menguntungkan bagi operasional Pusat Batik Banyumasan. Side entrance ditentukan berada di sekeliling samping dan belakang tapak dengan pertimbangan entrance untuk fungsi kegiatan servis (lihat Gambar 2).

\subsection{Analisis Pemintakatan}

1. Tujuan: zona ruang.

2. Dasar pertimbangan: analisis peruangan, analisis pengolahan tapak, analisis struktur.

3. Proses analisis:

Pertimbangan mintakat terkait kedekatan hubungan ruang didasarkan pada analisa peruangan yang sudah dilakukan sebelumnya (lihat Gambar 3).

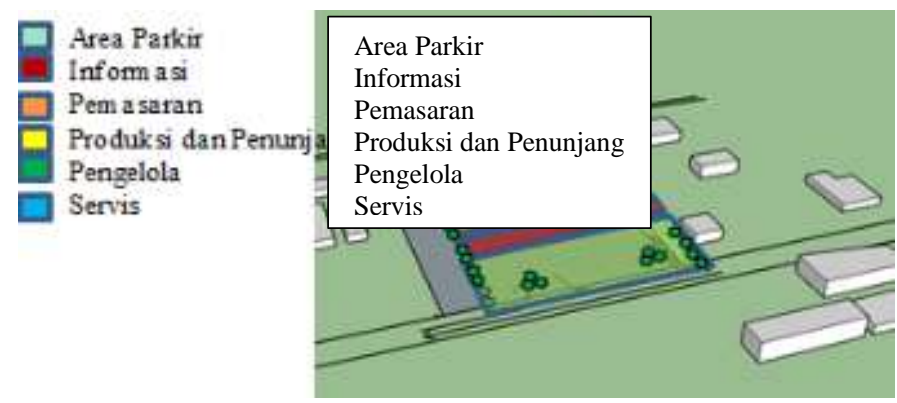

Gambar 3. Analisis Pemintakan

\subsection{Analisis Bentuk dan Tampilan Bangunan}

\subsubsection{Analisis Bentuk Bangunan}

1. Tujuan: bentuk bangunan.

2. Proses analisis:

Citra pada tampilan bangunan diambil dari perencanaan Pusat Batik Banyumasan yang direncanakan menggunakan prinsip-prinsip Kearifan Lokal berupa rumah srotong (Widyandini, 2010).

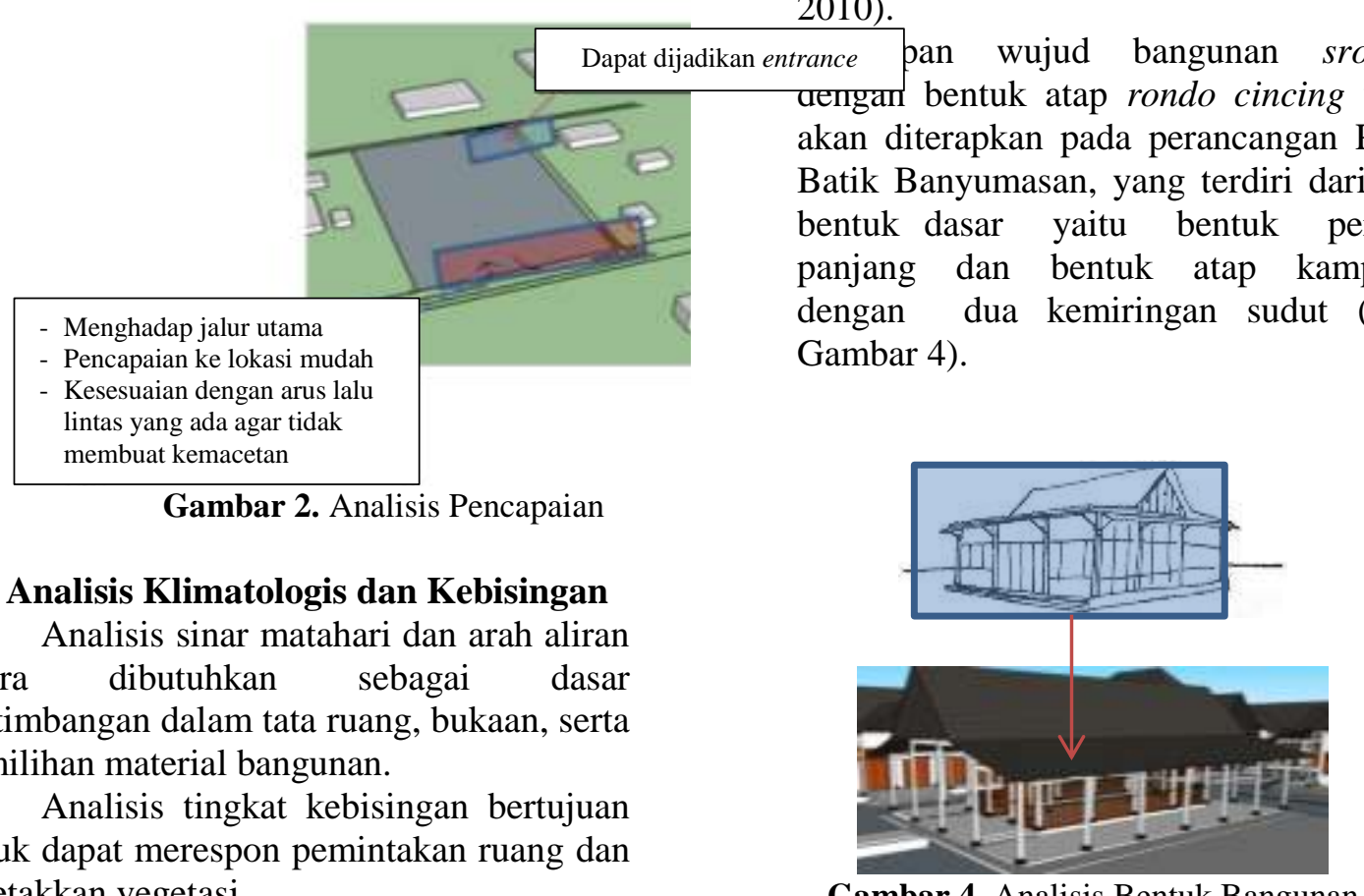

Gambar 4. Analisis Bentuk Bangunan 
Bentuk massa kegiatan pemasaran sebagai inti utama bangunan Pusat Batik

Banyumasan juga menerapkan bentuk rumah srotong dengan tata ruang bangunan yang mengadaptasi dari pola ruang rumah srotong (lihat Gambar 5 dan 6).

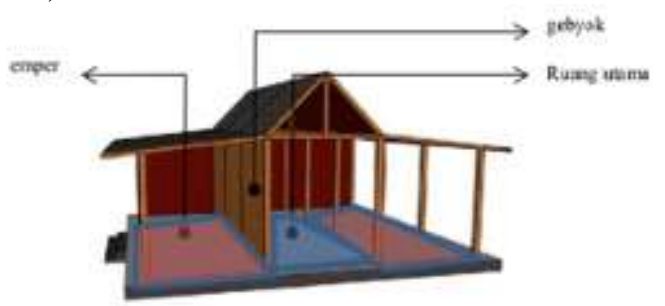

Gambar 5. Pola Ruang Rumah Srotong

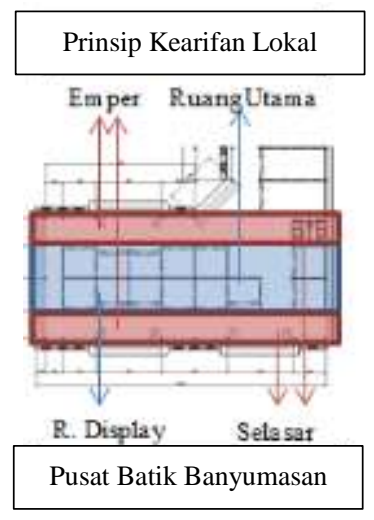

Gambar 6. Analisis Bentuk Bangunan

\subsubsection{Analisis tampilan bangunan}

1. Tujuan: tampilan bangunan.

2. Proses analisis:

Kesan Banyumasan akan ditampilkan melalui material, ragam hias, dan warna.

Material yang digunakan di Pusat Batik Banyumasan adalah material yang mudah ditemukan di Banyumas. Jenis material lokal tersebut yaitu batu kali, kayu, batu bata, genting, pasir dan kerikil (lihat Gambar 7).

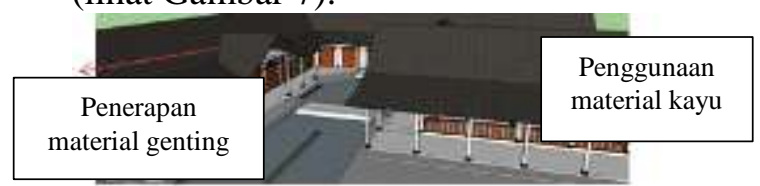

Gambar 7. Analisis Penggunaan Material

Penggunaan material lokal seperti kayu dan bambu yang mudah diperoleh di Banyumas dan sekitarnya merupakan perwujudan wujud Kearifan Lokal yang cocok untuk diterapkan terhadap bangunan (lihat Gambar 8).

Ornamen-ornamen tersebut masingmasing memiliki arti dan makna pada setiap jenisnya. Berikut merupakan aplikasi ornamen pada ruang:

a. Ornamen dengan desain pola batik yang diaplikasikan pada dinding di area tertentu.

b. Ragam hias yang digunakan pada masyarakat Banyumas meliputi ragam hias flora, fauna, alam, dan religi, seperti Lung-lungan, Ular Naga, Panah, dll (Cahyandari, 2007).
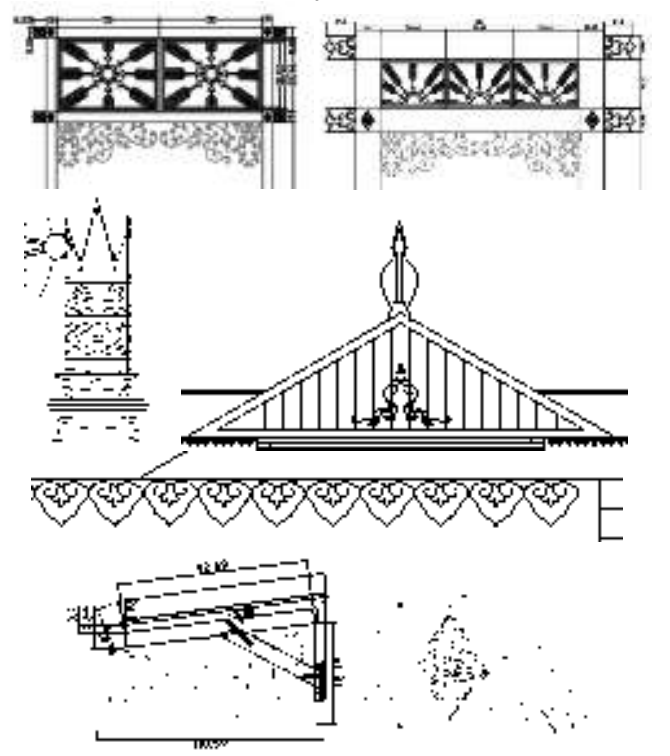

Gambar 8. Tampilan Bangunan

\subsection{Analisis Struktur}

\subsubsection{Struktur bawah}

1. Tujuan: pondasi bangunan.

2. Dasar pertimbangan: struktur bangunan bertingkat rendah dan kondisi tanah pada bangunan.

3. Proses analisis:

Sub struktur yang sesuai untuk bangunan yang direncanakan, yaitu pondasi batu kali untuk bangunan satu lantai.

\subsubsection{Struktur tengah}

1. Tujuan: struktur hadan bangunan.

2. Dasar Penggunaan gan: memiliki fleksibili material kayu gan dan ekonomis, dan kemampuan menahan gaya-gaya lateral dan kekakuan.

3. Proses analisis: struktur rangka dengan kolom, kolom praktis, dan balok sebagai pemikul beban merupakan struktur badan untuk bangunan yang direncanakan.

\subsubsection{Struktur atas}

a. Tujuan: struktur atap.

b. Dasar pertimbangan: kondisi bangunan eksisting. 
c. Proses analisis: atap yang akan digunakan, yaitu atap kampung dengan modifikasinya (atap rumah). Pada penerapannya, Pusat Batik Banyumasan ini menggunakan atap kuda-kuda kayu sebagai pengembangan struktur atap yang biasanya digunakan pada rumah srotong (lihat Gambar 9).

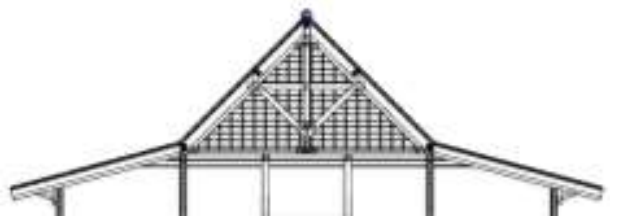

Gambar 9. Analisis Struktur Atap

\section{KESIMPULAN}

Konsep rancangan Pusat Batik Banyumasan mengacu pada konsep pendekatan Kearifan Lokal. Dari hasil analisa serta hasil korelasi dari beberapa data di atas, maka diperoleh hasil berupa rancangan Pusat Batik Banyumasan di Purwokerto sebagai berikut:

\subsection{Bentuk}

Penerapan bentuk atap rondo cincing, yang terdiri dari dua bentuk dasar yaitu bentuk persegi panjang dan bentuk atap kampung dengan dua kemiringan sudut (lihat Gambar 10).

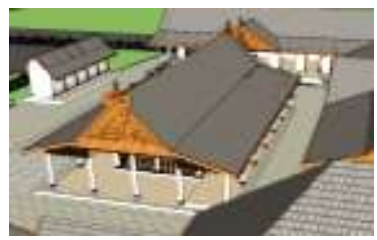

Gambar 10. Bentuk Atap

\subsection{Warna}

Warna diperoleh dari bahan bangunan asli maupun diolah (di cat/kapur). Bahan-bahan utama yang memunculkan karakter warna adalah kayu, bambu, genting, dan seng.

\subsection{Tata Elemen Arsitektural}

Penerapan beberapa ornamen pada elemen arsitektural di Pusat Batik Banyumasan (lihat Gambar 11).

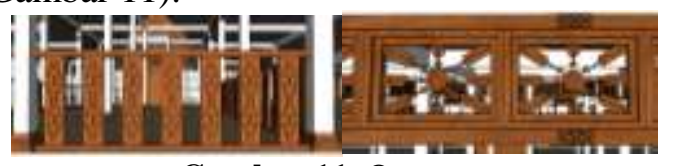

\subsection{Struktur}

Gambar 11. Ornamen

Penerapan struktur pada bangunan menggunakan struktur atap kuda-kuda yang disesuaikan dengan atap rumah srotong (lihat Gambar 12).

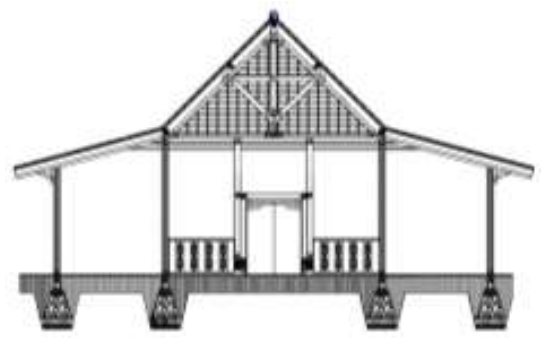

Gambar 12. Potongan Bangunan
Lokasi
: J1. Supardjo Rustam
Luas Lahan
$: 8.000 \mathrm{~m}^{2}$
Luas Bangunan : $5.000 \mathrm{~m}^{2}$
Kegiatan : Promosi, produksi, dan pemasaran batik.

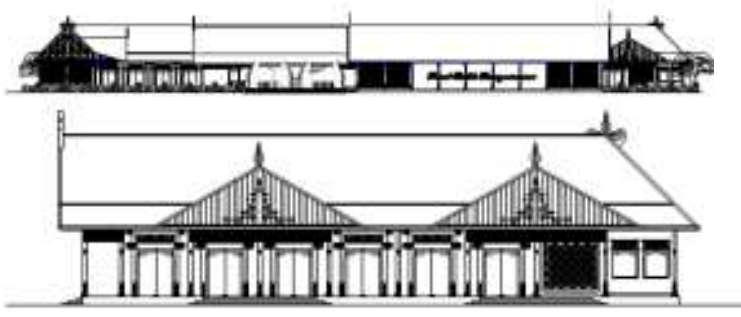

Gambar 13. Tampak Bangunan

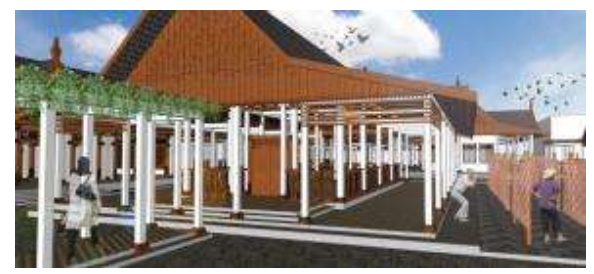

Gambar 14. Eksterior Bangunan

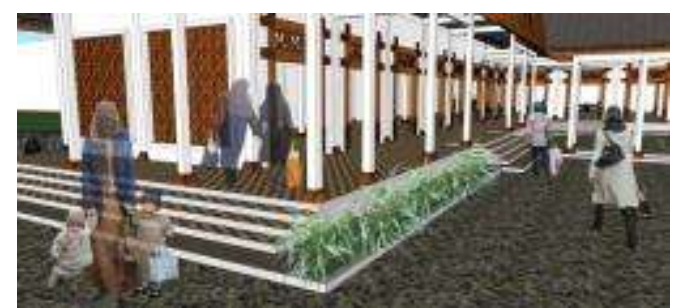

Gambar 15. Eksterior Bangunan

\section{REFERENSI}

Cahyandari, G.O.I . 2007. Tata Ruang dan Elemen Arsitektur pada Rumah Jawa sebagai Wujud Kategori Pola Aktivitas dalam Rumah Tangga. Yogyakarta: Laporan Penelitian Dikti Kajian Wanita

Widyandini, Wita, Nurswening, Yohana. 2010. Tinjauan Arsitektur Tradisional Jawa di Kota Lama Banyumas Teodolita Vol.12, No. 1., Juni 2010: 22-37. Puwokerto: Universitas Wijayakusuma Purwokerto 